\title{
CATALOGUING OF MEDIEVAL MANUSCRIPTS IN GERMAN LIBRARIES: THE ROLE OF THE DEUTSCHE FORSCHUNGSGEMEINSCHAFT (DFG) AS A FUNDING AGENCY ${ }^{1}$
}

From the NINETEENTH CENTURY ONWARD, German librarians have devoted considerable effort to the cataloguing of medieval manuscripts, ${ }^{2}$ many of which came into public ownership after the secularization of monasteries at the beginning of the century. The centralization of sources stimulated scholarly interest in the material, to which librarians responded by compiling inventories and catalogues. Due to the size of the collections, which were often augmented by further acquisitions from the antiquarian book market in the second half of the century, the authors of those early catalogues had to restrict themselves to recording only the most essential codicological data and textual information. While some libraries with large collections published comprehensive, yet fairly rudimentary, catalogues, ${ }^{3}$ smaller collections were often not catalogued at all or only described in local, handwritten inventories. Depth and precision of catalogue records varied considerably, as no

1. This paper was originally presented at the second conference of the LIBER (Ligue des Bibliothèques Européennes de Recherche) Expert Group of European Manuscript Librarians, held at The Hague on 5-8 March 2003. See http://www.kb.nl/coop/liber/mss/.

2. In this article, the term manuscripts refers to handwritten medieval and early modern books or fragments of such books that form part of library collections. Medieval charters and other documents preserved in archival collections do not fall within the scope of the DFG's program for manuscript cataloguing.

3. See, for example, the manuscript catalogues of the Bayerische Staatsbibliothek München by Karl Halm (Catalogus codicum latinorum Bibliothecae Regiae Monacensis [Munich, 1868-]) and Erich Petzet (Die deutschen Pergamenthandschriften Nr. 1-200 der Staatsbibliothek in München [München, 1920]), of the University Library at Heidelberg by Karl Bartsch (Die altdeutschen Handschriften der Universitäts-Bibliothek in Heidelberg [Heidelberg, 1887]), of the Württembergische Landesbibliothek Stuttgart by Wilhelm von Heyd (Die Handschriften der Königlichen Öffentlichen Bibliothek zu Stuttgart [Stuttgart, 1889-]), and of the Staatsbibliothek Berlin by Valentin Rose (Verzeichniss der lateinischen Handschriften der Königlichen Bibliothek zu Berlin [Berlin 1893-]) and Hermann Degering (Kurzes Verzeichnis der germanischen Handschriften der Preussischen Staatsbibliothek [Leipzig, 1925-]). 
uniform standard for cataloguing existed. Furthermore, catalogues and inventories rarely reflected the progress of scholarship concerning the collections; instead, libraries recorded new insights and publications in annotated copies of the catalogues or in separate card indices, both of which were, again, only available locally or on written application.

After World War Two, energetic steps were taken to amend this situation. On the one hand, collections had been removed during the war to secure storage, or dispersed, or even destroyed as a result of military action. Stock-taking became a necessity when the collections were returned to their previous homes. On the other hand, the need for more detailed, scholarly catalogues was felt strongly, as academic interest in medieval studies grew continually. As a result of West Germany's federal structure, there was, however, no central institution that could take charge of such a nationwide program. Unlike the East German Democratic Republic, the West German Federal Republic lacked both a National Library and a National Academy that could have assumed a central steering role. Although regional and local traditions had to be respected, common standards were required to achieve a uniformly high level of quality. In response to this need and in recognition of the importance of manuscripts as part of the national cultural heritage, the Deutsche Forschungsgemeinschaft (DFG) ${ }^{4}$ set up a funding program for manuscript cataloguing projects all over Germany and administered these grants through a panel of experts who were responsible for developing standards, as well as procedures, for quality control.

Initially created in 1920 as the Notgemeinschaft der Deutschen Wissenschaft (Emergency Association of the German Scholarly Community), but deprived of its independent status in academic politics by the National Socialists, the Deutsche Forschungsgemeinschaft resumed work as the central public funding organization for academic research in $1951 .^{5}$ Comparable to a research council or a (national) research foundation, the DFG is an autonomous organization within the German academic community. Legally a private association under civil law, its members are universities, research institutions (such as the Max-PlanckGesellschaft), the Academies of Science, and scholarly associations. The private status of the DFG was determined to guarantee the self-management of research funding by the academic community. As the largest

4. http://www.dfg.de.

5. For the history of the DFG, see http://www.dfg.de/dfg_im_profil/geschichte/. 
administrator of grants to academic institutions in Germany, for more than half a century the DFG has played a central role in the development of policies for access to information on a national level. In recent years, and especially with the advent of the Internet as a powerful information provider, this perspective has been more and more widened to include an international community of users.

In order to fulfill its goals, the DFG oversees a budget that in 2002 totaled 1.267 million Euros. ${ }^{6}$ Contributions come mainly from the federal government (about $60 \%$ overall) via the Bundesministerium für Bildung und Forschung and the governments of the Länder (about 40\%). Although financed by the government, the DFG is not a government agency. At the moment, it funds some 25,000 projects, including fellowships. Policy development and decision-making by the DFG follow a "bottom-up" approach based on the principle that responsibility for scientific and scholarly work rests with the scholars carrying out this work in their various institutional settings. The principle of the DFG's evaluation of project grant applications is peer review. The backbone of the evaluation system is the panels of experts whose members are elected by the German academic community. All decisions to fund projects are based entirely on the recommendations of these panels. At the central DFG headquarters in Bonn, some 650 staff members assist the panels of experts in the development and coordination of grant programs and provide support for the applicants and the panel members. The programs that have been created to support the work of academics at different stages in their career, from Ph.D. students to Nobel Prize winners, award grants for individual scholars and for cooperative projects. With a view to improving the academic infrastructure, both in the sciences and the humanities, special funding programs have been set up for expensive technical equipment and for academic libraries.

Research, especially in the humanities, requires libraries that continually improve their collections and services in order to make primary sources, secondary literature, and new electronic forms of information accessible to the user both efficiently and cost-effectively.

In Germany, responsibility for academic libraries rests primarily with the sixteen regional governments. They provide the main and basic funding, whereas the DFG only funds projects of national significance

6. For details, see the annual report at http://www.dfg.de/jahresbericht/auf_erg.htm. 
and of special relevance for the academic community. Therefore, the main priority of the DFG's subsection for academic libraries (recently renamed Academic Literature Supply and Information Systems) ${ }^{7}$ is the creation of user-friendly information systems that respond to the needs of the academic community. In the electronic age, this requires the application of innovative information technology even in areas that have hitherto been dominated by conventional forms of access. In order to facilitate this transition, new infrastructures must be built that combine the advantages of long-established methodological approaches with the new facilities for communication and cooperation. The inclusion of international partners in this process not only broadens the user base of this work, thus improving the ratio of cost and benefit, but also enhances the quality of the services provided. In order to achieve these ambitious aims, the DFG's panels of experts for libraries, whose members are senior librarians and academics from both Germany and abroad, develop a framework of policy concepts and recommendations that form the basis of funding programs. Within these programs, individual projects can be funded if they are approved by the panels of experts. Unlike funding for academic projects, funding in the area of information systems is not granted to individual scholars or groups of academics, but to institutions that are responsible for infrastructure (usually libraries, archives, or comparable institutions).

Manuscript books are probably the artifacts from the medieval period that have survived up to the present day in the largest numbers. The texts and images recorded in them document the intellectual and, to some extent, the popular traditions of European culture far more comprehensively than any other source. Although not limited to the cultural heritage of one country, medieval manuscripts have always been regarded as objects of national importance. Therefore, the DFG set up a funding program in 1960 to make all surviving manuscripts in German libraries available for international research through the publication of collection-oriented catalogues of high scholarly quality. Within the framework of this national program for manuscript cataloguing, organizational methods and standards have been developed that have contributed substantially to Germany's reputation as a country with excellent resources for medievalists.

7. http://www.dfg.de/forschungsfoerderung/wissenschaftliche_infrastruktur/lis/. 
Today, manuscript cataloguing is mainly carried out at five libraries that have strong holdings of both manuscripts themselves and of reference literature in medieval studies: the Staatsbibliothek zu Berlin-Preußischer Kulturbesitz, ${ }^{8}$ the Stadt- und Universitätsbibliothek Frankfurt, ${ }^{9}$ the Universitätsbibliothek Leipzig, ${ }^{10}$ the Bayerische Staatsbibliothek München, ${ }^{11}$ and the Württembergische Landesbibliothek Stuttgart. ${ }^{12}$ At each of these "centers for manuscript cataloguing," several cataloguing projects are in progress at any given time, some of which involve the center's own holdings, while others deal with manuscripts belonging to smaller libraries in the vicinity that have been temporarily transferred to the center. This organizational structure ensures that cataloguers have access to a large body of material for comparative study in areas such as paleography and codicology, to unedited texts, as well as to comprehensive and up-to-date research literature and information resources. Furthermore, cataloguers enjoy the benefits of exchanging information with expert colleagues. The manuscript librarian in charge of the center is responsible for quality control. The centers thus play an important role in maintaining a balance between local traditions and national coordination. In order to address the concerns of those libraries with substantial collections that are reluctant to transfer manuscripts to a cataloguing center, as well as those libraries with sufficient local expertise, the DFG can, in exceptional cases, also grant funding to projects not located at a center. In such cases, however, the library in question has to conform to national cataloguing standards and guarantee a high quality of cataloguing. In total, about forty projects run simultaneously, with an average duration of six years during which about 150 medieval manuscripts are catalogued. All projects must submit annual reports to the DFG, including samples of catalogue descriptions that are evaluated by a panel of experts composed of experienced manuscript librarians and academic medievalists who represent various disciplines.

The standards for manuscript cataloguing are codified in the guidelines "Richtlinien Handschriftenkatalogisierung,"13 which have undergone four revisions since they were first published in 1963, reflecting the ex-

8. http://handschriften.staatsbibliothek-berlin.de/de/projekte/abendlaendische_handschriften/3.html.

9. http://www.stub.uni-frankfurt.de/hsn/hsnzentr.htm.

10. http://www.ub.uni-leipzig.de/Wir_ueber_uns/sosa/HSZ.htm.

11. http://www.bsb-muenchen.de/handruck/handschr.htm\#Katalogisierung.

12. http://www.wlb-stuttgart.de/archive/handschriften.htm.

13. Deutsche Forschungsgemeinschaft: Richtlinien Handschriftenkatalogisierung. 5. Aufl. Bonn-Bad Godesberg 1992. Online: http://www.dfg.de/forschungsfoerderung/wissenschaftliche_infrastruktur/lis/veroeffentlichungen/index.html\#7 and http://www.manuscripta-mediaevalia.de/hs/richtlinien.htm 
perience gained through an increasing number of projects. During that process, the "Richtlinien" developed from rather vaguely formulated recommendations to a more prescriptive cataloguing manual, which, however, still allows considerable flexibility to reflect the individual features of a manuscript or a collection. Over the years, specific guidelines were developed for particular types of manuscripts (such as illuminated manuscripts, early modern manuscripts, or manuscripts of polyphonic music) and, more recently, new forms for accessing their descriptions are being made available. Since the 1980s, cross-catalogue searching techniques have gradually been developed, originally in the form of a cumulative index to manuscript catalogues published as microfiche under the title "Freiburger Index" (later "Gesamtindex"). This necessitated a common standard for indices to manuscript catalogues, with more consistent codicological terminology and a standard structure for index entries (main entries, subordinate entries, and cross-references). Strict terminological control became even more crucial when the cumulative index was made accessible in electronic form. Since the inception of the DFG program for manuscript cataloguing, the "Richtlinien" have formed the basis of more than 200 printed catalogues, covering collections ranging from Aachen to Zwickau and as diverse as Munich and Fritzlar. Eventually, all these catalogues will be accessible online. ${ }^{14}$

The transition from printed catalogue and cumulative index in microform to a searchable database has been the most serious change affecting the work of manuscript cataloguers and researchers in the past decade. The advent of the personal computer and the availability of the Internet have had wide-reaching consequences for existing practices and standards in manuscript departments. On the one hand, the new technology for electronic catalogue production and distribution has increased the number of catalogue users as well as the speed with which the results of cataloguing work can be accessed; on the other hand, such technology has required a much more rigid application of common standards, as the points of divergence between individual practices become increasingly obvious and can potentially prevent information that does not conform to the standard from being accessible. The time-consuming process of agreeing on best practices and enhancing the user-friendliness of electronic tools for cataloguing and retrieval is likely to continue for yet some time, and although the regular introduction of software updates is necessary, it inevitably increases the need for more consultation and coordination.

14. See http://www.manuscripta-mediaevalia.de/hs/kataloge-online.htm. 
Not only technical factors necessitated change in the DFG's program for manuscript cataloguing. At a political level, the reunification of Germany has had enormous impact not only on external conditions (such as the growing competition for increasingly limited funding), but also on the scope of the coordinated program. The number of collections has increased to include those in the former German Democratic Republic, which held a substantial amount of uncatalogued or insufficiently catalogued material. In order to close these gaps within a reasonable time, a more flexible approach to cataloguing had to be developed, thus leading to more methodological diversity. The development of the information society has led to a growing demand for better public access to our cultural heritage. The Internet has become a truly popular forum that allows all citizens to benefit personally from public spending in this area, for example, by gaining direct access to electronic reproductions of treasures that are physically only available to a small elite. Such a broadening of interest can be very beneficial to the provider of the material because wider presence in the public perception should make it easier to gain support and sponsorship. This is especially relevant at a time when the search for funding and staff is becoming more competitive within institutions. External partnerships, be they academic or popular, improve the status of manuscript departments within a library and beyond, and the DFG encourages project organizers to develop such networks both nationally and internationally.

In consideration of these factors, the DFG recently revised its policies with regard to manuscript cataloguing. In 2000, the DFG's library panel set up an expert group to develop new concepts for how manuscript collections can best be accessed. Their findings were published in 2001 and are available for consultation on the DFG Web site. ${ }^{15}$

The work of the expert group was based on the following premises:

- The World Wide Web is the central medium for presentation, distribution, retrieval, and integration of information systems. All information sources that are required for research should be networked there. Access for scholars should be free and open.

15. Neue Konzepte der Handschriftenerschließung: Informationssysteme zur Erforschung des Mittelalters und der Frühen Neuzeit, 2001: http://www.dfg.de/forschungsfoerderung/wissenschaftliche_infrastruktur/lis/veroeffentlichungen/index.html\#7 
- Online information resources for medievalists should include manuscript catalogues, both those funded by the DFG and older catalogues, as well as collection-oriented documentation of research literature on manuscripts.

- Complete coverage of German manuscript collections is to be the goal. Overall holdings are estimated at about 60,000 volumes, of which two-thirds are covered by DFG funded and older (pre-DFG) catalogues. The remaining third is still in need of cataloguing using modern standards.

- Different levels of cataloguing (inventories, in-depth catalogues, etc.) have to be applied in order to achieve this within a reasonable time and at reasonable cost.

- New ways of cooperation with academic users, such as interactive exchange of information, ought to be explored.

- In order to benefit from research in related disciplines, nonmanuscript materials such as printed books, but also information on bindings and watermarks, should be integrated into more comprehensive information systems for medievalists.

- Digital reproductions ought to supplement catalogue records in order to make primary material accessible more immediately and more widely.

- In order to enhance the international aspect of German research, information systems should be equipped with multilingual user interfaces.

As a consequence of the work done by the expert group, projects for manuscript cataloguing were redefined in terms of :

- scope and content,

- methodological standards,

- presentation and distribution of results, and

- user orientation and evaluation. 


\section{Scope and Content of Projects}

The scope and content of projects is today much wider than ever before. In addition to traditional projects for the in-depth cataloguing of a particular collection or group of manuscripts, the DFG now also supports projects for creating less-detailed inventories of manuscripts and for the retroconversion of older printed catalogues. This greater flexibility in cataloguing methodology results from the need to provide complete coverage of manuscript holdings in German libraries within a reasonable time. Methods of cataloguing must now be adapted to the type and the profile of the collection. Although inventories can provide initial access to little-known collections and to smaller holdings in a particular region, in-depth cataloguing is still the method of choice for collections of outstanding importance and special research interest to scholars.

Due to the shortage of funding and experienced staff, as well as to the inevitable length of time involved in compiling detailed descriptions of manuscripts, the highest level of cataloguing can only be applied to a small proportion of the medieval manuscripts in German libraries. For many collections, however, older printed catalogues that were compiled before the DFG program exist and, although they do not conform to the current standards of the DFG, can nevertheless be of substantial quality and comprehensiveness. Often such historical catalogues are only accessible in a few special research libraries. In order to facilitate access to them, regardless of a scholar's location, the DFG is providing funding for the retroconversion of such materials. In a pilot project, different conversion methods were tested: Approximately 180 catalogues were scanned as digital images and are now available for browsing and searching by means of indices, whereas eleven other catalogues have been converted into full-electronic text. ${ }^{16}$ Retroconversion has shown that the most serious problem that presents itself is the considerable variability of information. Differences between the older descriptions and those that are currently being produced exist not only with regard to their structure, but also in their content: Ascriptions of authorship and text titles have been modified, transcription varies as much as the terminology of codicological descriptions, and indices in the past have not always included relevant categories of information such as incipits of texts. Such discrepancies become even more obvious when catalogues are combined into a comprehensive database, which can lead to considerable frustration and dissatisfaction on the part of their users. To

16. See http://www.manuscripta-mediaevalia.de/hs/kataloge-online.htm. 
overcome this problem, a considerable amount of editing has to be done by hand. The hope is that automated solutions will be developed in the future (e.g., intelligent retrieval tools that will rely on sophisticated cross-references or methods such as searching for phrases with similar spelling).

As a supplement to electronic catalogue descriptions, the DFG encourages the digitization of other bibliographical material (e.g., local collections of reference literature on manuscripts) and of the primary sources themselves. For decades, most manuscript departments have recorded publications on their holdings in card indices arranged by shelf mark. These were originally designed for internal information only but were generally available to users for consultation. Now these can be converted into electronic form by scanning the indices as images or by rekeying them. In some circumstances, they are even linked to digital versions of the original materials or to records in the local library OPAC. ${ }^{17}$ Thus, researchers can assemble secondary information on a given manuscript while online and sometimes even read those articles during the same online session. But at the very least, they can find the location of a monograph that has been referenced. In the future, interactive interfaces might even allow users to supplement information that is on the database. Pilot projects are currently under way in Munich and Hamburg, using substantially different methodologies, as the technical solutions vary depending on local catalogue systems and the way in which they cross-link with OPACs. Also, the means for integrating electronic descriptions and digital reproductions of manuscripts is not yet fully developed. But in due course, it is hoped that such integrated information systems will become a reality.

Digital reproductions of manuscripts are a convenient tool for accessing information that is hard to convey in descriptive texts, such as the characterization of script and analysis of layout. Collections suitable for digitization must be well defined, sufficiently well known, and catalogued in order to estimate the research interest in them and to link scholarly catalogue descriptions with the digital images. So far, two pilot projects for the digitization of selected groups of medieval manuscripts have

17. See e.g. http://www.bibliothek.uni-augsburg.de/sonder/fordok.html. For further information on this and related projects, see Günter Hägele, *Die "Neuen Konzepte der Handschriftenerschließung" und die Forschungsdokumentation der Universitätsbibliothek Augsburg* (http://www.dfg.de/forschungsfoerderung/wissenschaftliche_infrastruktur/lis/veroeffentlichungen/dokumentationen/hs_tagung_2002.html). 
been funded by the DFG: digitization of the approximately 400 manuscripts of the cathedral library of Cologne ${ }^{18}$ and twenty-seven fifteenthcentury illuminated manuscripts from the workshop of Diebold Lauber. ${ }^{19}$ Both projects have taken quite different approaches to the work in terms of organization and cataloguing methodology, resulting in highly dissimilar cost models. Within the framework of digitization projects for historical sources in German libraries in general, it is now necessary to evaluate those methodological approaches, as well as the usage of the material by scholars and other users, in order to determine the scope of future projects in this area, in terms of both the finances and staff required and the selection and presentation of the material.

The DFG also encourages libraries and archives to make auxiliary material for manuscript-related research available via the Internet. Such information has often been gathered in institutions over long periods of time in the form of conventional archives without closely coordinating the work and with little access for external users. Frequently, the material is too voluminous to lend itself for publication in conventional form; electronic access is much more suitable and convenient. One example for such a DFG project is the German database for rubbings of fifteenth- and sixteenth-century blind-tooled bindings, a cooperative project of the libraries at Berlin, Stuttgart, and Wolfenbüttel, with other partners due to join in the near future. ${ }^{20}$ Another is the archive of watermark tracings compiled by Gerhard Piccard and now converted into an online database. ${ }^{21}$ For the integration of such resources into manuscript catalogues, persistent identifiers (reference numbers) of objects in these databases are required that will allow cross-linking between manuscript descriptions and information on bindings or paper.

\section{Methodological Standards}

The greater diversity of projects outlined above inevitably leads to a wide variety of standards, with respect to both their technical basis and their content. Although large projects will establish de facto standards in a particular area, short-term projects often do not allow sufficient time for the documentation of work procedures. Therefore, a common best practice must be agreed upon in order to facilitate the exchange

18. http://www.ceec.uni-koeln.de/.

19. http://www.ub.uni-heidelberg.de/helios/fachinfo/www/kunst/digi/lauber/\#Kap3.

20. http://www.hist-einband.de/.

21. http://www.lad-bw.de/. 
of information and allow for cross-database searching. For the storage of both images and descriptions, various data formats exist. Because interoperability and long-term sustainability are the key issues, criteria must be developed to determine the suitability of data formats for manuscript projects.

With regard to manuscript descriptions, the "Richtlinien Handschriftenkatalogisierung" 22 is a well-established standard for in-depth cataloguing of medieval text manuscripts, illuminated manuscripts, and manuscripts of polyphonic music; however, similar guidelines do not yet exist for summary descriptions in inventories. In the past, inventories have followed different models (censuses, summary catalogues, etc.), and this flexibility will need to be retained because projects differ immensely with regard to the preliminary situation. The nature of existing indices and repertories, as well as the composition of the manuscript collection itself, must be taken into account. ${ }^{23}$ Catalogues that cover both medieval and early modern manuscripts can combine the methods of in-depth cataloguing and summary description. In other cases, those approaches are successive steps in the course of work on a large collection of previously unknown material. In the first phase, an inventory is created, which forms the basis for selecting the material that requires in-depth cataloguing. In the course of a project, targets can thus be readjusted according to the work process and in response to external influences such as user needs or the availability of funds.

The pilot projects for digitization of manuscripts have shown that major methodological issues are still unresolved. On the question of whether to digitize from the original or via a photographic intermediary, in color or black and white, the opinions of conservators and technicians are divided. Issues of long-term sustainability of digital data, their life expectancy, and potential costs of conversion also are controversial. The expenses incurred in digitization make it unlikely that digital reproductions of manuscripts will ever be available on a comprehensive scale. However, it is expected that cataloguing projects will increasingly be accompanied by the production of digital reproductions of selected manuscripts.

22. See above note 13

23. See the proceedings of a recent workshop on the topic: Rundgespräch zu methodischen Problemen bei der Inventarisierung mittelalterlicher Handschriften, Stuttgart, 4.April 2003 (http://www.dfg.de/forschungsfoerderung/wissenschaftliche_infrastruktur/lis/veroeffentlichungen/index.html\#7). 


\section{Presentation and Distribution of Results}

Although the advantages of electronic publication in terms of speed, cost, and ease of access are indisputable, printed catalogues are still the only medium that can guarantee the long-term availability of the project results. Therefore, the DFG continues to provide funding for the publication of catalogues in both printed and electronic format. However, in accordance with general DFG policy, a financial ceiling for publication grants has had to be imposed. This decision is a consequence of the increasing costs of academic publications as well as a reaction to what is seen as the DFG funding the same project several times: at the point of production (research grants) and distribution (subsidies for publishers and support for library acquisition budgets). By reducing such subsidies, the DFG intends to stimulate the development of systems for free electronic or cost-effective printed publications by the academic or library community itself.

As a central medium for the electronic publication of manuscript descriptions, the Manuscripta Mediaevalia database has received DFG funding since $1996 .^{24}$ The nucleus of the database was the cumulative index to postwar German manuscript catalogues, initially published as microfiche and later converted into a database, which was first hosted at the Deutsches Bibliotheksinstitut (DBI) (and therefore known as DBILink). After the dissolution of the institute in 1999, the database was transferred to the Bildarchiv Foto Marburg, where it migrated to a new software environment. The manuscript database is now run as a shared project by the Bildarchiv and the State Libraries in Berlin and Munich, both of which are responsible for the data input of current and retroconverted manuscript catalogues. All manuscript projects that receive funding from the DFG are expected to make their descriptive information accessible through the database. At the moment, however, only a few do so by direct input into the database; in most cases, descriptions are uploaded after the completion of a cataloguing project. Although this is a time-consuming process, it does allow for centralized editorial control. Tasks ahead include the improvement of the database interfaces for both input and retrieval; the introduction of nonproprietary data formats for import and export; and the development of functional tools for the costeffective production of printed catalogues, which, even though no longer the predominant medium for the distribution of project results, still play an important role in documenting and distributing scholarly knowledge.

24. http://www.manuscripta-mediaevalia.de (follow link "Datenbank"). 


\section{User Orientation and Evaluation}

With libraries having become important partners in the worldwide information network, manuscript projects should grasp the opportunity to seek more direct and active ways of reaching their users. Distributing information via the Web sites of libraries and cataloguing centers or through mailing lists has already become standard practice for most libraries. To enhance the international perception of the activities, multilingual user interfaces need to be developed for these Web-based services. In addition, interactive forms of communication must be established to help improve the quality of the resources by seeking advice from experts and allowing projects to be tailored better to user needs. For evaluating the efficiency of projects, statistical information on the usage of electronic services can be useful (e.g., data collected in log files), even though it cannot always be interpreted conclusively. At a time of growing financial restrictions imposed on both those institutions giving and those receiving grants, it is more important than ever to coordinate efficiently the available means in terms of funding and staff in order to achieve results of high quality and relevance, which can be reliably sustained into the foreseeable future. The DFG will continue to play an important role in this process. 